\title{
Maritime container logistics and onshore transportation systems (Part 2)
}

\author{
Ek Peng Chew • Hans-Otto Günther • \\ Kap Hwan Kim · Herbert Kopfer
}

Published online: 8 June 2012

(C) Springer Science+Business Media, LLC 2012

The last decade has seen tremendous investments in new container ports, vessels, and linked onshore transportation systems. Due to the high level of customer service requested and the complexity of logistic processes in seaport container terminals, many terminal operators have attempted to improve the performance of their terminals by applying new technologies including automated equipment, advanced information technologies, and optimization techniques. The demand for these new technologies has been further intensified as the size of deep-sea vessels gets larger and coastal and landside transportation systems are linked to major container ports. As a result, global freight networks are emerging which combine maritime transport, inland waterways and onshore road and rail transportation systems.

The primary objective of this special issue is to reflect the recent developments in maritime and landside container transport and to examine research issues concerned with quantitative analysis and decision support for container terminal logistics and freight transportation systems. For the second part of the special issue six papers

\section{E. P. Chew}

Department of Industrial and Systems Engineering, National University of Singapore, 1 Engineering Drive 2, Singapore, Singapore

e-mail: isecep@nus.edu.sg

\section{H.-O. Günther $(\bowtie)$}

Department of Production Management, Technical University of Berlin, Straße des 17. Juni 135, 10623 Berlin, Germany

e-mail: hans-otto.guenther@tu-berlin.de

\section{K. H. Kim}

Department of Industrial Engineering, Pusan National University, 30 Changjeon-Dong,

Kumjeong-Ku, Busan 609-735, Korea

e-mail: kapkim@pusan.ac.kr

\section{H. Kopfer}

Department of Logistics, University of Bremen, Wilhelm-Herbst-Straße 5, 28359 Bremen, Germany e-mail: kopfer@uni-bremen.de 
have been selected for publication after a thorough peer-review according to the standards of the FSM journal. In addition one erratum is included. The first part with the following papers has been published in Volume 23 (2011), Number 4, of FSM.

- Do Ngoc, A. D., Moon, I.-K.: The storage capacity expansion and space leasing for container depots

- Douma, A. M., Schuur, P. C., Schutten, J. M. J.: Aligning barge and terminal operations using service-time profiles

- Wang, S. Wang, T., Meng, Q.: A note on liner ship fleet deployment

The following additional accepted papers are available for download from the publisher's webpage at http://www.springerlink.com/content/1936-6590 and will appear in the third part of the special issue in due course.

- Dekker, R., van der Heide, S., van Asperen, E., Ypsilantis, P.: A chassis exchange terminal to reduce truck congestion at container terminals

- van Asperen, E., Borgman, B., Dekker, R.: Evaluating impact of truck announcements on container stacking efficiency

- Nam, H., Lee, T.: A scheduling problem for a novel container transport system: a case of mobile harbor operation schedule

- Shin, K., Lee, T.: Container loading and unloading scheduling for a Mobile Harbor system: a global and local search method

- Wiese, J., Suhl, L., Kliewer, N.: An analytical model for designing yard layouts of a straddle carrier based container terminal

- Kulak, O., Polat, O., Gujjula, R., Günther, H.-O.: Strategies for improving a long-established terminal's performance: a simulation study of a Turkish container terminal

\section{Papers in part 2 of the special issue}

The first paper by $J$. Kim and J. R. Morrison gives an overview of recent developments in offshore port service concepts. The authors propose a classification scheme of non-traditional offshore solutions, and discuss the advantages, disadvantages and the related container handling chain. In particular, the so-called "mobile harbour" concept is addressed. In order to investigate the economic feasibility of this idea, an estimate of the cost per unit threshold is developed below which this concept will be viable. Comparisons with alternate concepts reveal the competitiveness of the "mobile harbour".

The erratum on this paper adds an acknowledgment for providing research funds which was inadvertently omitted in the original publication and provides some additional remarks on the interpretation of the numerical results.

The subsequent paper by M. P. M. Hendricks, D. Armbruster, M. Laumanns, E. Lefeber and J. T. Udding considers the berth allocation problem of a terminal operator who provides container handling services at multiple terminals within the same port. A practical solution approach based on mixed-integer programming is developed that spreads a set of cyclically calling vessels over the various terminals 
and allocates a berthing and departure time to each of them. The objectives are to balance the quay crane workload over the terminals and to minimize the amount of inter-terminal container transport. Numerical results based on a case study from the port of Antwerp are presented.

In their paper L. P. Ku, E. P. Chew, L. H. Lee and K. C. Tan propose a novel approach for yard planning under vessel arrival uncertainty. Specifically, they develop a two-stage modeling approach for the allocation of storage capacity to containers in the yard where the stage 1 decision is made before the uncertainty is revealed, and stage 2 is a recovery of the stage 1 solution, after the uncertainty is revealed. As the considered problem is of high complexity, heuristic procedures are proposed to solve the sub-problems. The major advantage of this yard planning approach is that a solution can be found that allows the terminal operator to easily react on uncertainty in the arrival of vessels.

The design of the service network in intermodal barge transport is studied in the paper by A. Caris, C. Macharis and G. K. Janssens. Its major contribution is the development of a new methodology to analyze the cooperation between inland terminals along the same waterway. The hinterland network is studied as a whole to see whether or not inland terminals in the network should cooperate. Selected cooperation schemes are evaluated by means of a discrete event simulation model and compared with simulation results of bundling in the port area. Experimental results reveal that a combination of bundling measures in the port area and in the hinterland may be necessary to improve the intermodal transport chain.

C.-Y. Lee and $M . Y u$ address the problem of price competition between the container terminal and a remote container yard for temporary storage of inbound containers. They propose pricing game models between the container terminal and a remote container yard. Two cases are considered: price-independent and pricedependent container dwell time. The mathematical modeling provides operational insights into the effectiveness of the storage pricing behavior and competition outcomes of the container terminal and the remote container yard.

The final paper by L. Blander Reinhardt and D. Pisinger presents an exact solution method for the container shipping network design problem taking into account the costs of transshipment, a heterogeneous fleet, route dependent capacities, and butterfly routes. The problem is solved with branch-and-cut using clover and transshipment inequalities. The developed branch-and-cut method can be used for planning the routes of a smaller shipping company such as a feeder company or for planning a region of the network of a bigger liner shipping company. Since the algorithm finds optimal solutions it can also be used to benchmark heuristic algorithms.

\section{Concluding remarks}

This special issue has greatly benefited from the cooperation among the authors, reviewers, and editors. We would like to express our sincere thanks to the reviewers for their excellent and timely refereeing. Last, but not least, we thank all authors for their contributions which made this special issue possible. 